\title{
Strontium mono-chloride - A new molecule for the determination of chlorine using high-resolution graphite furnace molecular absorption spectrometry and direct solid sample analysis
}

\author{
Éderson R. Pereira ${ }^{a}$, Bernhard Welz ${ }^{\text {a,b,* }}$, Alfredo H.D. Lopez ${ }^{\text {a }}$, Jefferson S. de Gois ${ }^{a}$, Giovanni F. Caramori ${ }^{\text {a }}$, \\ Daniel L.G. Borges ${ }^{\mathrm{a}, \mathrm{b}}$, Eduardo Carasek ${ }^{\mathrm{a}, \mathrm{b}}$, Jailson B. de Andrade ${ }^{\mathrm{b}}$ \\ a Departamento de Química, Universidade Federal de Santa Catarina, 88040-900 Florianópolis, SC, Brazil \\ b Instituto Nacional de Ciência e Tecnologia do CNPq, INCT de Energia e Ambiente, Universidade Federal da Bahia, 40170-115 Salvador, BA, Brazil
}

\section{A R T I C L E I N F O}

\section{Article history:}

Received 13 August 2014

Accepted 17 September 2014

Available online 28 September 2014

\section{Keywords:}

Chlorine determination

Biological samples

HR-CS GF MAS

Direct solid sample analysis

TD-DFT calculation

\begin{abstract}
A B S T R A C T
A new method has been developed for the determination of chlorine in biological reference materials using highresolution continuum source graphite furnace molecular absorption spectrometry (HR-CS GF MAS) of the strontium mono-chloride $(\mathrm{SrCl})$ molecule and direct solid sample analysis. The use of the $\mathrm{SrCl}$ molecule for high-temperature MAS was not described up to now in the literature. Preliminary time-dependent density functional theory calculations of the $\mathrm{SrCl}$ structure were carried out in order to obtain reasonable estimates of the absorption spectrum of the target molecule. The calculations, which were carried out at BHandHLyp/def2QZVP level of theory, proved a very accurate and inexpensive way to get information about the spectrum of the $\mathrm{SrCl}$ molecule, which enabled us to perform the $\mathrm{Cl}$ determination with good sensitivity and specificity. The molecular absorption of the $\mathrm{SrCl}$ molecule has been measured using the wavelength at $635.862 \mathrm{~nm}$, and zirconium and palladium have been evaluated as the chemical modifiers in order to increase the sensitivity of the gaseous $\mathrm{SrCl}$ molecule generated in the graphite furnace. The pyrolysis and vaporization temperatures were $600{ }^{\circ} \mathrm{C}$ and $2300{ }^{\circ} \mathrm{C}$, respectively. Accuracy and precision of the method have been evaluated using biological certified reference materials of both animal and plant origins, showing good agreement with the informed and certified values. Limit of detection and characteristic mass were 1.0 and $2.2 \mathrm{ng}$, respectively. The results found using HR-CS GF MAS were in agreement (95\% confidence level) compared to those obtained by electrothermal vaporization-inductively coupled plasma mass spectrometry.
\end{abstract}

co 2014 Elsevier B.V. All rights reserved.

\section{Introduction}

Chlorine is among the 20 most frequent elements found in the earth's crust, and it is, after fluorine and oxygen, the third most reactive non-metal. One of the biggest reserves of chlorine is the oceans, where it is dissolved mostly as $\mathrm{NaCl}$ at an average concentration of $3-3.5 \%$. Chlorine, in the form of negatively charged chloride ions, is an essential element for humans, animals and plants. Chloride ions play an important role in the acid-base equilibrium of our body, the water balance and the secretion of the stomach and the kidney. Sodium chloride was a valuable merchandise for millenniums, as it was used for example for the conservation of food. Chlorine is also one of the most important base products of chemical industry, for example for the production of poly-vinyl chloride and many other products.

The diatomic gas $\mathrm{Cl}_{2}$ is a greenish-yellow gas with corrosive, oxidizing and disinfectant properties; the gas and its derivatives are applied

\footnotetext{
* Corresponding author at: Departamento de Química, Universidade Federal de Santa Catarina, 88040-900 Florianópolis, SC, Brazil. Fax: +55 4837216850.

E-mail address: w.bernardo@terra.com.br (B. Welz).
}

for several purposes, such as water disinfection, paper bleaching, and even in the manufacture of chemical weapons $[1,2]$. Compounds of chlorine might be highly toxic; in the presence of water $\mathrm{Cl}_{2}$ can be converted to hydrochloric acid, which causes besides pulmonary and mucous membrane irritation, some serious injuries to the eyes, nose, throat and lungs [1]. Clinical symptoms appear instantly after the exposure to chlorine and may consist of nasal discharge, lacrimation and pain in the upper airways. Concentrations of only $0.01 \% \mathrm{Cl}_{2}$ in the air can cause death and even a concentration of $0.001 \%$ can cause lung damages [2].

Due to its importance for life and its potential toxic effects, monitoring chlorine concentrations in biological tissues is very important. Chloride ions can be determined with classical methods, such as gravimetric, volumetric or colorimetric procedures. Nowadays, chlorine is usually determined using instrumental techniques, such as instrumental neutron activation analysis [1], inductively coupled plasma optical emission spectrometry [3,4], inductively coupled plasma mass spectrometry (ICP-MS) [5,6], X-ray fluorescence spectrometry [7], and molecular fluorescence spectrometry [8]. However, some sample pretreatment is normally required for most of these techniques. 
The most suitable sample pretreatment techniques for posterior $\mathrm{Cl}$ determination include combustion techniques $[9,10]$, acid digestion [11], extraction and dilution procedures after alkaline fusion [12,13]. The main disadvantages of sample pretreatment are related to the need of additional equipment, reagents, and the possibility of contamination and analyte loss. The last is critical for acid digestion due to the formation of volatile compounds [11].

Another technique for the determination of chlorine is molecular absorption spectrometry (MAS), which was first proposed by Haraguchi and Fuwa [14] using a flame and a conventional atomic absorption spectrometer for the determination of In-containing diatomic molecules ( $\mathrm{InF}$, InCl, InBr). Later, Dittrich et al. [15] used MAS for the determination of $\mathrm{Cl}$ in a graphite furnace via the $\mathrm{AlCl}$ molecule; however, they had to use liquid-liquid extraction of the analyte to get reasonable results due to the low resolution and the limited background correction possibilities of the equipment. Due to the limitations of conventional equipment for atomic absorption spectrometry (AAS), the technique was only used by a very limited group of researchers and never accepted for routine analysis.

This situation changed completely after the introduction of highresolution continuum source AAS (HR-CS AAS), which uses a highintensity continuum radiation source, a high-resolution double monochromator and a charge-coupled device (CCD) array detector. With this kind of equipment, any wavelength between 190 and $900 \mathrm{~nm}$ is available for analytical measurements at high resolution. Huang et al. [16] reported the determination of chlorine with this technique using an airacetylene flame and the molecular absorption of the InCl molecule. Heitmann et al. [17] determined chlorine in a graphite furnace via the $\mathrm{AlCl}$ molecule and Fechetia et al. [18] used the same technique and the same molecule to determine $\mathrm{Cl}$ in food samples. In both publications, the sample was digested before the analysis, and in the latter one chlorine was precipitated as $\mathrm{AgCl}$ and re-dissolved in ammonia before the analysis, and various modifiers were added for the final determination.

Obviously, any kind of sample pretreatment and addition of reagents increases the risk of contamination, as chloride is present in many reagents. Aiming to solve the problems related to sample pretreatment, direct analysis of solid samples (SS) can be applied as essentially no sample pretreatment is required. Thus, the use of reagents is not necessary, the possibility of contamination and analyte loss are reduced, and the analytical frequency is higher. Direct SS analysis can be successfully coupled to AAS; however determining $\mathrm{Cl}$ in such a way is not suitable once its analytical lines are in the vacuum UV below $190 \mathrm{~nm}$ [19].

Given these circumstances, MAS combined with direct SS analysis might be a suitable technique for the indirect determination of halogens via their diatomic molecules formed in the gas phase [19-24]. Highresolution continuum source molecular absorption spectrometry using a graphite tube furnace (HR-CS GF MAS) appears to be a feasible way to determine chlorine. The electron excitation spectra of diatomic molecules are comprised of many more lines than atomic spectra, containing three types of energy: electronic energy $\left(E_{\mathrm{el}}\right)$, vibrational energy $\left(E_{\mathrm{vib}}\right)$ and rotational energy $\left(\mathrm{E}_{\mathrm{rot}}\right)$, all of which are completely or almost completely resolved by a high-resolution spectrometer [19]. Due to the high temperature in a graphite furnace or in a flame only diatomic molecules are considered to exist. It has been demonstrated that molecules such as PO and CS are formed spontaneously [19], whereas mono-halogens, such as $\mathrm{AlCl}[18,25]$ and $\mathrm{InCl}[16,26]$, are only formed upon the addition of a molecule-forming reagent in large excess [19].

In the case of $\mathrm{Cl}$, only $\mathrm{AlCl}[17,18,25]$ and $\mathrm{InCl}[16,26]$ molecules were reported in the literature, which were generated from an aqueous solution in a graphite furnace and a flame, respectively. However, both band heads are not ideal for MAS, as they are relatively broad, which makes background correction more difficult, and they are in a spectral range ( $\mathrm{InCl}$ at 267.24 and $\mathrm{AlCl}$ at 261.42) where the risk for an overlap with atomic lines (e.g. Co [17]) is relatively high. Hence, it was considered worthwhile to investigate other diatomic molecules for the determination of chlorine, and one possible candidate was the $\mathrm{SrCl}$ molecule, which still has a relatively high dissociation energy of $409 \mathrm{~kJ} \mathrm{~mol}^{-1}$.

One of the problems faced in the determination of chlorine via HRCS GF MAS is that there is very little information available about electronic absorption spectra of $\mathrm{SrCl}$. Some data obtained through high-technology devices (e.g. conjunction of time-resolved atomic resonance fluorescence and molecular chemiluminescence techniques) shed some light on the gas phase $\mathrm{SrCl}$ molecule spectrum but little was said about which of the absorption bands or lines could be used for MAS purposes. In this sense, we opted for performing preliminary density functional theory (DFT) calculations and its time-dependent extension (TD-DFT) [27] in order to estimate reasonably the bandwidth and position of maxima of $\mathrm{SrCl}$ absorption spectra.

Thus, this work describes the use of TD-DFT [28] calculations to predict the absorption region of the strontium mono-chloride $(\mathrm{SrCl})$ molecule and future chlorine determination by HR-CS GF MAS with direct SS analysis. The direct SS analysis has been investigated in order to minimize sample preparation, while the strontium has been used both as a molecule forming reagent and a chemical modifier. Another advantage is also to use aqueous standard solutions for calibration, which dispense the use of certified reference materials providing speed and lower cost.

\section{Materials and methods}

\subsection{Theoretical approach}

The geometric parameters, including internuclear distance and harmonic vibrational frequencies of the $\mathrm{SrCl}$ optimized ground-state structure as well as the energies and orbital occupancies of the first excited states were obtained at BHhandHLyp [29,30]/def2-QZVP [31] level of theory, using effective core potential (ECP) approximation [32], to describe the inner shells of the $\mathrm{Sr}$ atom. Ground-state calculations were performed with DFT (BHhandHLyp [29,30]/def2-QZVP [31]), whereas excited state descriptions were obtained using its time dependent variation TD-DFT (BHhandHLyp [29,30]/def2-QZVP [31]). The absorption spectrum of the $\mathrm{SrCl}$ molecule was obtained by using the IMDHOT [33]: the independent mode displaced harmonic oscillator model which takes into account the influence of finite temperature on the bandwidth and position of maximum in the spectra. All calculations and spectra simulation were carried out with ORCA 3.0. package [34].

BhandHlyp [29,30], a hybrid GGA functional, was already shown to exhibit an excellent performance in describing electric moments and the cartesian components of the (hyper)-polarizability of diatomic molecules [35], apart from being equally accurate in describing the non-bonded interactions such as hydrogen-bonds and charge-transfer interactions [36]. The sort of calculations used herein successfully allow the prediction of the vibrational structure of the electronic spectra of real systems and can be used routinely to achieve valuable information about spectroscopic properties of (even exotic) chemical species.

\subsection{Instrumentation}

A Model contrAA 600 high-resolution continuum source atomic absorption spectrometer (Analytik Jena AG, Jena, Germany), with a transversely heated graphite tube atomizer was used in all measurements. The instrument is equipped with a xenon short-arc lamp with a nominal power of $300 \mathrm{~W}$, operating in a hot-spot mode, which emits a high-intensity continuous spectrum within the wavelength range from 189 to $900 \mathrm{~nm}$. The optical compartment, consisting of a highresolution double monochromator: a prism pre-monochromator and an echelle grating monochromator, providing a spectral bandwidth per pixel of about $1.6 \mathrm{pm}$ at $200 \mathrm{~nm}$, and a linear CCD array detector with 588 pixels, 200 of which are used for analytical purposes, displaying the vicinity of the analytical line at high resolution. The $\mathrm{SrCl}$ 
molecule measurements were carried out at $635.863 \mathrm{~nm}$ by using the sum of the integrated absorbances of three pixels (peak volume selected absorbance, PVSA, $\left.A_{\sum 3, \text { int }}\right)$.

Pyrolytically coated graphite tubes with a PIN platform (Analytik Jena, Part No. 407-A81.025), were used initially for the optimization of the method with aqueous standard solutions while tubes without platform (Analytik Jena, Part No. 407-A81.303), were used in all experiments with direct SS analysis. The solid samples were weighed directly onto SS platforms (Analytik Jena Part No. 407-152.023), treated with a permanent modifier, using an M2P microbalance (Sartorius, Göttingen, Germany). A manual solid sampling system, SSA 6 (Analytik Jena), was used to insert the SS platforms into the graphite tube. The optimized temperature program used for all determinations with HRCS SS-GF MAS is shown in Table 1.

The measurements using SS and electrothermal vaporization (ETV) ICP-MS were carried out with an Elan 6000 inductively coupled plasma mass spectrometer, equipped with an HGA-600 MS electrothermal vaporizer (Perkin-ElmerSCIEX, Thornhill, Canada), coupled to a solid sampler (Bodenseewerk Perkin-Elmer, Überlingen, Germany) that works similar to a syringe pipette [37], and the "cup-in-tube" technique described by Völlkopf et al. [38]. The samples were directly introduced into quartz capillaries, weighed using an M2P microbalance (Sartorius) and transferred to pyrolytic graphite coated sample cups, which were introduced into the graphite tube (Perkin-Elmer, Norwalk, USA). The operating parameters of the ICP-MS were published elsewhere [39]. Argon gas with a minimum purity of $99.996 \%$ (White Martins, São Paulo, Brazil) was used as plasma, carrier and internal gas flow of the ETV.

\subsection{Reagents and reference material}

Distilled and deionized water with a resistivity of $18 \mathrm{M} \Omega \mathrm{cm}$, obtained from a Model Mega ROUP (Equisul, Pelotas, Brazil) purification system was used for the preparation of the standard solutions and dilution. A reference stock solution of $\mathrm{Cl}$ with $1000 \mathrm{mg} \mathrm{L}^{-1}$ was prepared by dissolving appropriate amounts of $\mathrm{NaCl}$ (Fluka, Buchs, Switzerland) in purified water. A stock solution containing $10 \mathrm{~g} \mathrm{~L}^{-1}$ $\mathrm{Sr}^{2+}$ was prepared by dissolving appropriate amounts of $\mathrm{SrCO}_{3}$ (Vetec, Duque de Caxias, Brazil) in 5\% v/v acetic acid and used as the molecule-forming reagent. Zirconium (Fluka) and palladium (Fluka) solutions of $1000 \mathrm{mg} \mathrm{L}^{-1}$ were used as permanent chemical modifiers.

The following biological certified reference materials (CRM) BCR 186 Pig kidney and BCR 278R Mussel tissue (Community Bureau of Reference, Brussels, Belgium); NIST SRM 1567a Wheat flour, NIST SRM 1577b Bovine liver and NIST RM 8414 Bovine muscle powder (National Institute of Standards and Technology, Gaithersburg, MD, USA); and NCS ZC 71001 Beef liver (NACIS, Beijing, China), were used for method validation.

\subsection{Procedure in HR-CS SS-GF MAS}

The SS platforms were first coated with a layer of $\mathrm{Zr}$ or Pd, which served as a permanent chemical modifier. For this purpose, $40 \mu \mathrm{L}$ of a stock solution containing $1000 \mu \mathrm{g} \mathrm{L}^{-1} \mathrm{Zr}$ or Pd was deposited on the platform, which was then inserted into the graphite tube. The first

Table 1

Temperature program used for $\mathrm{Cl}$ determination as $\mathrm{SrCl}$ via molecular absorption using HR-CS GF MAS; an argon gas flow rate of $2.0 \mathrm{~L} \mathrm{~min}^{-1}$ was used in all stages, except during vaporization, where the internal gas flow was turned off.

\begin{tabular}{lccc}
\hline Stage & Temperature $/{ }^{\circ} \mathrm{C}$ & Ramp $/{ }^{\circ} \mathrm{C} \mathrm{s}$ & Hold $/ \mathrm{s}$ \\
\hline Drying 1 & 90 & 30 & 20 \\
Drying 2 & 130 & 30 & 20 \\
Pyrolysis & 600 & 50 & 10 \\
Vaporization & 2300 & 3000 & 5 \\
Cleaning & 2400 & 100 & 4 \\
\hline
\end{tabular}

four stages of the temperature program shown in Table 2 were executed and the platform was allowed to cool. This procedure was repeated 10 times, and after the last injection the entire temperature program shown in Table 2 was executed, resulting in the deposition of a total of $400 \mu \mathrm{g}$ modifier on the platform. The biological CRM $(\approx 0.05-0.5 \mathrm{mg})$ were weighed directly onto the SS platforms, previously treated with a permanent chemical modifier. Ten microliters of the moleculeforming $\mathrm{Sr}^{2+}$ solution, corresponding to $100 \mu \mathrm{g} \mathrm{Sr}$ was injected over the biological samples on the SS platform and introduced into the graphite furnace to be submitted to the temperature program in Table 1. Calibration was directly against aqueous standard solutions, $20 \mu \mathrm{L}$ of the $\mathrm{NaCl}$ standard solution and $10 \mu \mathrm{L}$ of the molecule-forming $\mathrm{Sr}^{+}$solution were deposited on the SS platform treated with the permanent modifier and the same temperature program shown in Table 1 was applied.

\subsection{Procedure for SS-ETV-ICP-MS}

The biological CRM were weighed (about $0.5 \mathrm{mg}$ ) and transferred to the solid sampling cup, which was inserted into the graphite tube and submitted to the temperature program. External calibration against the solid RM 8414 was performed using the mass range from 0.2 to $1.5 \mathrm{mg}$ reference material. The temperature program of the electrothermal vaporizer consisted of a drying stage at $100{ }^{\circ} \mathrm{C}$ for $10 \mathrm{~s}$, a pyrolysis stage at $600{ }^{\circ} \mathrm{C}$ for $10 \mathrm{~s}$ and a vaporization stage at $1800{ }^{\circ} \mathrm{C}$; the cleaning temperature was $2000{ }^{\circ} \mathrm{C}$.

\section{Results and discussion}

\subsection{Selection of the analytical line}

The calculated ground-state inter-nuclear distance (2.595 $\AA$ ) and harmonic vibrational frequency $\left(299.7 \mathrm{~cm}^{-1}\right)$ were in good accordance with experimental data ( $2.576 \AA$ [40] and $300 \mathrm{~cm}^{-1}$ [41], respectively), indicating that BHandHLyp/def2-QZVP level of theory is adequate for describing the electronic structure of the $\mathrm{SrCl}$ molecule. The simulated absorption spectrum shown in Fig. 1, was generated using IMDHOT model, which demonstrates that there is an intense absorption around $636.8 \mathrm{~nm}$, which is consistent with the reported experimental data $[42,43]$. Additionally, a sequence of absorption lines is observed in the range from 600 to $660 \mathrm{~nm}$ due to different electronic, rotational and vibrational transitions of the $\mathrm{SrCl}$ molecule.

The next step was to evaluate experimentally the data that were obtained theoretically. Hence, the spectral range from 635 to $637 \mathrm{~nm}$ was investigated (with increments of $0.4 \mathrm{~nm}$ ), using a solution containing $20 \mathrm{ng} \mathrm{Cl}$ (as $\mathrm{NaCl}$ ) and $100 \mu \mathrm{g} \mathrm{Sr}{ }^{2+}$ as the molecule-forming reagent was injected into the graphite furnace, and a strong absorption of the $\mathrm{SrCl}$ molecule was observed in the vicinity of $635.862 \mathrm{~nm}$. This result is in good agreement with the theoretical calculation, presenting a slight difference of $0.952 \mathrm{~nm}$. In addition, the $\mathrm{SrCl}$ spectrum provides a sequence of absorption lines of lower sensitivity at shorter and higher wavelengths due to the different rotational transitions involved on the absorption process. Furthermore, these lines are located in a wavelength range with a relatively low risk of spectral interference because only a few atoms and molecules have absorption lines or bands in the

Table 2

Temperature program for the pre-treatment of the platform with a permanent chemical modifier. An argon gas flow-rate of $2.0 \mathrm{~L} \mathrm{~min}^{-1}$ was used in all stages.

\begin{tabular}{lccc}
\hline Stage & Temperature $/{ }^{\circ} \mathrm{C}$ & Ramp $/{ }^{\circ} \mathrm{C} \mathrm{s}^{-1}$ & Hold $/ \mathrm{s}$ \\
\hline 1 & 130 & 10 & 40 \\
2 & 160 & 10 & 50 \\
3 & 350 & 100 & 25 \\
4 & 1100 & 300 & 5 \\
5 & 2300 & 500 & 5
\end{tabular}




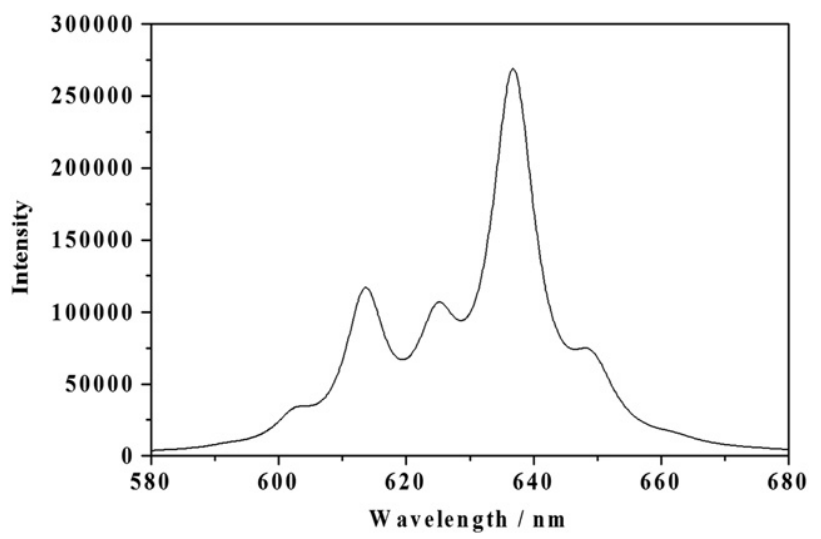

Fig. 1. Simulated absorption spectrum of the $\mathrm{SrCl}$ molecule generated using IMDHOT model.

visible spectral range. The molecular absorption spectrum of $\mathrm{SrCl}$ around the 635.862-nm line using HR-CS GF MAS is shown in Fig. 2.

\subsection{Optimization of pyrolysis and vaporization temperatures in an aqueous solution}

In preliminary studies, it was found that the use of permanent chemical modifiers, such as $\mathrm{Zr}$ and $\mathrm{Pd}$, increases the stability of the $\mathrm{SrCl}$ molecule in the pyrolysis and vaporization stages (Fig. 3). The pyrolysis and vaporization temperatures without modifier and using Pd modifier were around 1000 and $2100{ }^{\circ} \mathrm{C}$, respectively, while, when using $\mathrm{Zr}$ as a permanent chemical modifier, the pyrolysis and vaporization temperatures were 1200 and $2100{ }^{\circ} \mathrm{C}$, respectively. However, besides the slightly higher pyrolysis temperature, the main benefit of using $\mathrm{Zr}$ as a permanent modifier is the sensitivity of $\mathrm{SrCl}$, which was about 30\% higher than with an uncoated platform and about $17 \%$ higher using $\mathrm{Pd}$ as a permanent modifier. For this reason, $\mathrm{Zr}$ was selected as the permanent chemical modifier for future studies involving solid sampling.

\subsection{Optimization of conditions for direct SS analysis}

The goal of this work was the use of direct solid sample analysis for $\mathrm{Cl}$ determination in biological samples using, for the first time in HR-CS GF MAS, the absorption of the $\mathrm{SrCl}$ molecule. Fig. 4 shows the pyrolysis and vaporization curves using direct solid sample analysis. The

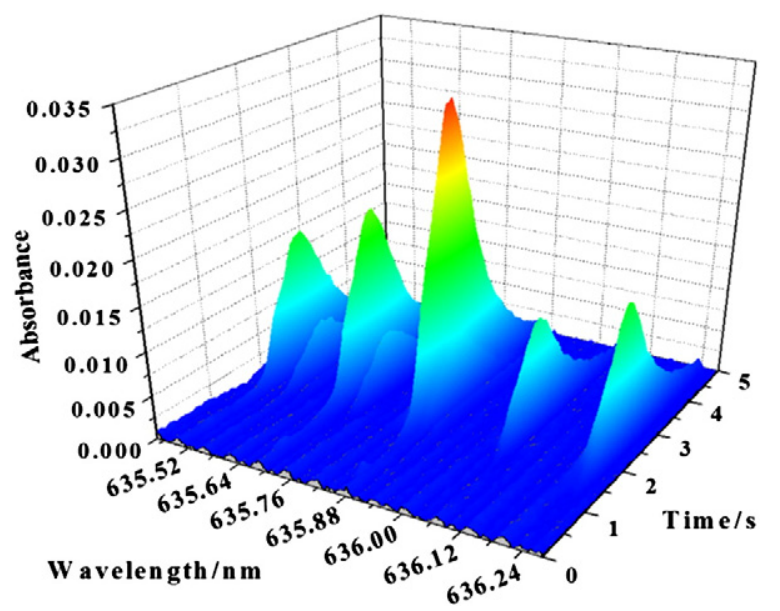

Fig. 2. Time-resolved absorbance spectrum of the $\mathrm{SrCl}$ molecule in the vicinity of the most sensitive line at $635.862 \mathrm{~nm}$ obtained from the vaporization of $20 \mathrm{ng} \mathrm{Cl}$ (as $\mathrm{NaCl}$ ) and addition of $100 \mu \mathrm{g} \mathrm{Sr}{ }^{2+}$ (as $\mathrm{SrCO}_{3}$ ) solution using a platform coated with $400 \mu \mathrm{g} \mathrm{Zr}$ as a permanent modifier.

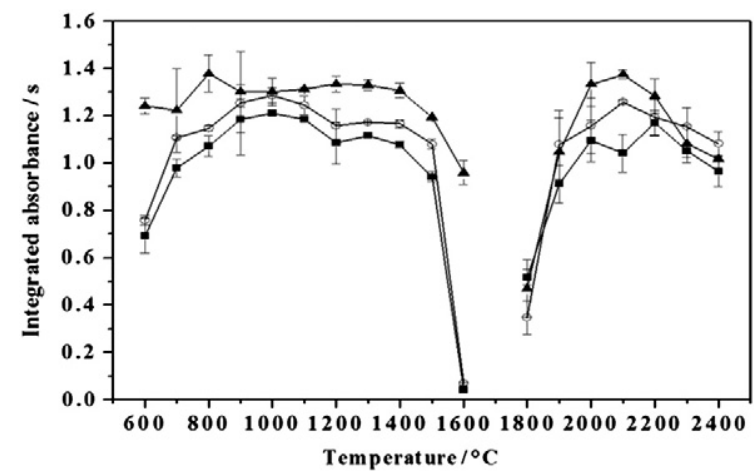

Fig. 3. Pyrolysis and vaporization $\left(\mathrm{T}_{\mathrm{pyr}}\right.$ and $\left.\mathrm{T}_{\mathrm{vap}}\right)$ curves for the $\mathrm{SrCl}$ molecule using an aqueous standard of $50 \mathrm{ng} \mathrm{Cl}\left(10 \mu \mathrm{L}\right.$ of $5 \mathrm{mg} \mathrm{L}^{-1}$ solution). For $\mathrm{T}_{\mathrm{pyr}}$ optimization, the $\mathrm{T}_{\text {vap }}$ was $2100{ }^{\circ} \mathrm{C}$, while for $\mathrm{T}_{\text {vap }}$ optimization the $\mathrm{T}_{\text {pyr }}$ was fixed at $1000{ }^{\circ} \mathrm{C}$ for $\mathrm{Pd}(\mathrm{O})$ and without modifier ( $\mathbf{\square})$ and at $1200{ }^{\circ} \mathrm{C}$ for $\mathrm{Zr}(\mathbf{\Delta})$. Strontium mass: $0.10 \mathrm{mg}(10 \mu \mathrm{L} 1 \%$ $\mathrm{m} / \mathrm{v} \mathrm{Sr}^{2+}$ solution). Each point represents the mean of three measurements; the error bars are plus/minus one standard deviation.

optimum pyrolysis temperature found in this study was $600{ }^{\circ} \mathrm{C}$, which is different from the one found for the aqueous standards (Section 3.2). This different behavior is probably associated with matrix compounds, which have a direct influence on the stability of chlorine compounds in the investigated samples. The less intimate contact of the molecule-forming reagent with the analyte in the case of solid samples, compared to the situation when they are mixed in solution, might be another explanation. Probably an increasing amount of $\mathrm{Cl}$ is lost above $600{ }^{\circ} \mathrm{C}$, which also explains the higher standard deviation in this range. In addition, the analytical signals become increasingly deformed, as can be seen in Fig. 5, which indicates that different vaporization mechanisms are active under these conditions. The optimum vaporization temperature using direct solid sample analysis and the $\mathrm{Zr}$ permanent modifier is about $2300{ }^{\circ} \mathrm{C}$

The $\mathrm{Sr}^{2+}$ mass was also evaluated in order to increase the sensitivity of $\mathrm{SrCl}$ molecule absorption. In this study, the $\mathrm{Sr}^{2+}$ mass investigated was $50,100,150$ and $200 \mu \mathrm{g}\left(5,10,15\right.$ and $20 \mu \mathrm{L}$ of the $10,000 \mathrm{mg} \mathrm{L}^{-1}$ $\mathrm{Sr}^{2+}$ solution), respectively. The results remained essentially constant and with good repeatability when $\mathrm{Sr}^{2+}$ masses higher than $100 \mu \mathrm{g}$ (10 $\mu \mathrm{L}$ of the $\mathrm{Sr}^{2+}$ solution) were used. Thus, the $\mathrm{Sr}^{2+}$ mass was fixed at $100 \mu$ p providing an excess of molecule-forming reagent.

The same pyrolysis and vaporization temperature program, optimized using around $0.05 \mathrm{mg}$ of solid RM 8414 (90 ng Cl absolute) was also applied to an aqueous standard solution containing $90 \mathrm{ng} \mathrm{Cl}(9 \mu \mathrm{L}$ of $10 \mathrm{mg} \mathrm{L}^{-1}$ solution), injected onto the platform. The analytical signal and integrated absorbance found for the aqueous standard solution and the solid sample using $600{ }^{\circ} \mathrm{C}$ for pyrolysis and $2300{ }^{\circ} \mathrm{C}$ for vaporization

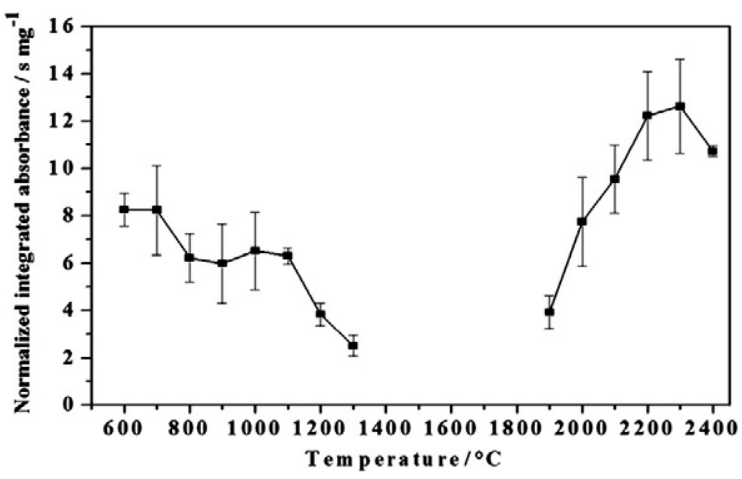

Fig. 4. Pyrolysis and vaporization curves for the $\mathrm{SrCl}$ molecule using direct solid sample analysis for $90 \mathrm{ng} \mathrm{Cl}$ (about $0.05 \mathrm{mg}$ of RM 8414) and $\mathrm{Zr}$ as the permanent modifier. For $\mathrm{T}_{\text {pyr }}$ optimization, the $\mathrm{T}_{\text {vap }}$ was $2100{ }^{\circ} \mathrm{C}$ while for $\mathrm{T}_{\text {vap }}$ optimization, the $\mathrm{T}_{\text {pyr }}$ was $600{ }^{\circ} \mathrm{C}$. Strontium mass: $0.10 \mathrm{mg}\left(10 \mu \mathrm{L} 1 \% \mathrm{~m} / \mathrm{v} \mathrm{Sr}^{2+}\right.$ solution). Each point represents the mean of three measurements; the error bars are plus/minus one standard deviation. 


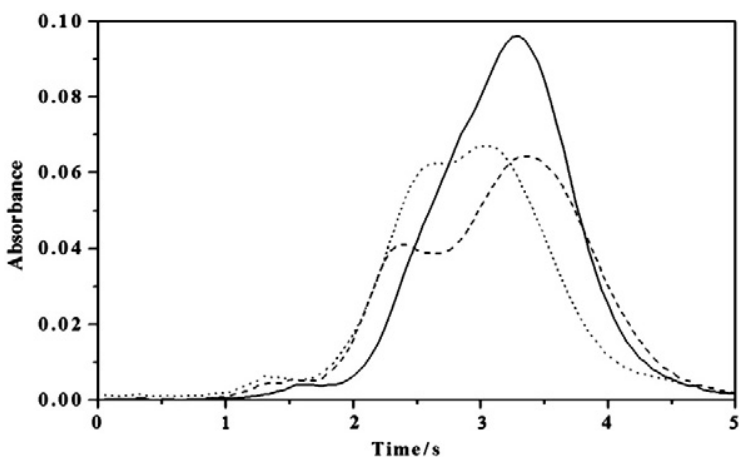

Fig. 5. Comparison of the time-resolved absorbance of the $\mathrm{SrCl}$ molecule, obtained for the vaporization of $90 \mathrm{ng} \mathrm{Cl}$ (about $0.05 \mathrm{mg}$ of RM 8414); $\mathrm{Zr}$ as the permanent modifier; $0.10 \mathrm{mg} \mathrm{Sr}\left(10 \mu \mathrm{L} 1 \% \mathrm{~m} / \mathrm{v} \mathrm{Sr}^{2+}\right.$ solution $)$; and $\mathrm{T}_{\text {vap }}$ of $2100{ }^{\circ} \mathrm{C}$. Solid line: $\mathrm{T}_{\mathrm{pyr}}=600{ }^{\circ} \mathrm{C}$; broken line: $\mathrm{T}_{\mathrm{pyr}}=700{ }^{\circ} \mathrm{C}$; dotted line: $\mathrm{T}_{\mathrm{pyr}}=800{ }^{\circ} \mathrm{C}$.

were very similar. It was found that the profile of the curves and the sensitivity for aqueous standards and solid samples were very similar as well; hence, calibration of solid samples against aqueous standard solutions appeared feasible.

\subsection{Calibration and figures of merit}

Besides evaluating the SS as the sample introduction, we also investigated the possibility of using aqueous standard solutions for calibration. The calibration curve using aqueous standards was linear within a mass range of 2 to $100 \mathrm{ng} \mathrm{Cl}$ with a slope of the calibration of $\mathrm{S}=0.0020 \mathrm{ng}^{-1} \mathrm{~s}^{-1}$ and linear correlation better than $\mathrm{R}=0.997$. The limit of detection (LOD) of the proposed method, calculated as 3 $\sigma / \mathrm{S}(\mathrm{n}=10)$, was $1.0 \mathrm{ng} \mathrm{Cl}$, where $\sigma$ is the standard deviation of 10 blank measurements and $\mathrm{S}$ is the slope of the calibration; the characteristic mass $\left(\mathrm{m}_{0}\right)$, calculated as $\mathrm{A}_{\mathrm{int}}=0.0044 \mathrm{~s} / \mathrm{S}$, was $2.2 \mathrm{ng}$, respectively.

\subsection{Determination of chlorine in CRM by HR-CS SS-GF MAS and ETV-ICP-} MS

The results of the indirect determination of $\mathrm{Cl}$ via the $\mathrm{SrCl}$ molecule by HR-CS GF MAS and direct SS analysis in different CRM using the procedure described in Section 2.4 are shown in Table 3. The same samples were also analyzed by SS-ETV-ICP-MS (refer to Section 2.5) [39], and no significant difference was found according to a Student's t-test $(p>0.05)$ between the found and the certified or indicative values for both methods. The main characteristic of the proposed method is the direct analysis of solid samples, which eliminates the need for any sample pre-treatment, which might be a potential source of contamination, generate waste and consume more time. Another advantage is the determination in the visible part of the spectrum, which is practically free of spectral interferences.

Table 3

Chlorine determination in biological CRM by HR-CS SS-GF MAS in comparison with SSETV-ICP-MS. The values represent the mean of five measurements \pm standard deviation (SD).

\begin{tabular}{lccl}
\hline \multirow{2}{*}{ CRM } & \multicolumn{2}{l}{ Concentration $(\% \pm$ SD $)$} & \multirow{2}{*}{ Certified (\%) } \\
\cline { 2 - 3 } & HR-CS GF MAS & ETV-ICP-MS $\left.{ }^{\mathrm{a}}\right)$ & \\
\hline NIST 8414 & $0.175 \pm 0.002$ & $0.192 \pm 0.018$ & $0.188 \pm 0.015$ \\
NIST 1577b & $0.280 \pm 0.050$ & $0.285 \pm 0.021$ & $0.278 \pm 0.006$ \\
NCS ZC 71001 & $0.28 \pm 0.03$ & $0.28 \pm 0.05$ & $0.29 \pm 0.04$ \\
NBS 1567a & $0.059 \pm 0.005$ & $0.051 \pm 0.009$ & $0.056^{\mathrm{b}}$ \\
BCR 186 & $0.86 \pm 0.08$ & $0.72 \pm 0.09$ & - \\
BCR 278R & $1.99 \pm 0.40$ & $2.22 \pm 0.12$ & - \\
\hline
\end{tabular}

\footnotetext{
a Values from Ref. [39].
}

b Indicative value.

\subsection{Considerations about the molecule stability}

Heitmann et al. [17] used strontium as a chemical modifier and not as a molecule-forming reagent in the determination of $\mathrm{Cl}$ by HR-CS GF MAS via the $\mathrm{AlCl}$ molecule. The authors also reported that satisfactory sensitivity was obtained using $\mathrm{Sr}^{2+}$ as a modifier, which reduces the volatilization of $\mathrm{Cl}$ in the pyrolysis stage. This approach is perfectly acceptable, since the dissociation energy of the $\mathrm{AlCl}$ molecule $\left(511 \mathrm{~kJ} \mathrm{~mol}^{-1}\right)$ is higher than that of the $\mathrm{SrCl}$ molecule $\left(409 \mathrm{~kJ} \mathrm{~mol}^{-1}\right)$. However, we believe that it is an advantage when $\mathrm{Sr}^{2+}$ is used as both the molecule-forming reagent and the chemical modifier, so that no other reagent has to be added, making the method very simple.

$\mathrm{Al}$ is present in this kind of samples only at trace level, so that no competitive formation of $\mathrm{AlCl}$ has to be expected. This can be observed in the determination of $\mathrm{Cl}$ in RM 8414, CRM NBS 1567a and NCS 71001 shown in Table 3, which have certified values of 1.7, 5.7 and $12 \mu \mathrm{g} \mathrm{g}^{-1}$ $\mathrm{Al}$, respectively. In these studies, the $\mathrm{Cl}$ recuperations were 94, 97 and $105 \%$, respectively, indicating that $\mathrm{Al}$ at this concentration level does not interfere in the $\mathrm{Cl}$ determination using $\mathrm{SrCl}$ for MAS.

\section{Conclusions}

The present work presents the development of a new method for the determination of $\mathrm{Cl}$, as $\mathrm{SrCl}$, using high-resolution continuum source graphite furnace molecular absorption spectrometry and zirconium as a permanent chemical modifier. Starting with a simple TD-DFT approach, the absorption spectra of the analyzed species could be reasonably estimated, presenting a maximum at $636.815 \mathrm{~nm}$, only slightly different from the one obtained experimentally (635.862 nm). The measurements were performed in the visible spectral region using the $\mathrm{SrCl}$ diatomic molecule in the gas phase, vaporized at $2300{ }^{\circ} \mathrm{C}$. Chlorine was determined using a calibration curve established with aqueous standard solutions, eliminating the use of certified reference materials for calibration. Moreover, the developed method proved to be accurate and precise when compared to ETV-ICP-MS and when applied to certified reference materials.

\section{Acknowledgments}

The authors are grateful to the Conselho Nacional de Desenvolvimento Científico and Tecnológico (CNPq), contract No. 305085/2011-5, and Coordenação de Aperfeiçoamento de Pessoal de Nível Superior (CAPES) for financial support and scholarships. The authors are also grateful to Analytik Jena for financial support and donation of the contrAA 600 high-resolution continuum source atomic absorption spectrometer.

\section{References}

[1] W.P. Bozeman, D. Dilbero, J.L. Schauben, Biologic and chemical weapons of mass destruction, Emerg. Med. Clin. North Am. 20 (2002) 975-993.

[2] J. Meulenbelt, Chlorine, Medicine 40 (2012) 117.

[3] H. Österlund, I. Rodushkin, K. Ylinenjärvi, D.C. Baxter, Determination of total chlorine and bromine in solid wastes by sintering and inductively coupled plasmasector field mass spectrometry, Waste Manage. 29 (2009) 1258-1264.

[4] S.S. Potgieter, L. Marjanovic, A further method for chloride analysis of cement and cementitious materials - ICP OES, Cem. Concr. Res. 37 (2007) 1172-1175.

[5] S.F. Boulyga, K.G. Heumann, Direct determination of halogens in powdered geological and environmental samples using isotope dilution laser ablation ICP-MS, Int. J. Mass Spectrom. 242 (2005) 291-296.

[6] J.H. Seo, M. Guillong, M. Aerts, Z. Zajacz, C.A. Heinrich, Microanalysis of S, Cl, and Br in fluid inclusions by LA-ICP-MS, Chem. Geol. 284 (2011) 35-44.

[7] J. Laursen, N. Milman, H.S. Petersen, G. Mulvad, E. Jul, H. Saaby, J.C. Hansen, Elements in autopsy liver tissue samples from Greenlandic Inuit and Danes. I. Sulphur, chlorine, potassium and bromine measured by X-ray fluorescence spectrometry, J. Trace Elem. Med. Biol. 12 (1998) 109-114.

[8] A. Doyle, A. Saavedra, M.L.B. Tristão, L.A.N. Mendes, R.Q. Aucélio, Spectrometric methods for the determination of chlorine in crude oil and petroleum derivatives a review, Spectrochim. Acta Part B 86 (2013) 102-107.

[9] Y.S. Fung, K.L. Dao, Oxygen bomb combustion ion chromatography for elemental analysis of heteroatoms in fuel and wastes development, Anal. Chim. Acta. 315 (1995) 347-355. 
[10] R.A. Nadkarni, D.M. Pond, Application of ion chromatography for determination of selected elements in coal and oil shale, Anal. Chim. Acta. 146 (1983) 261-266.

[11] E. Vassileva, H. Dočekalová, H. Baeten, S. Vanhentenrijk, M. Hoenig, Revisitation of mineralization modes for arsenic and selenium determinations in environmental samples, Talanta 54 (2001) 187-196.

[12] M. Novič, A. Dovžan, B. Pihlar, V. Hudnik, Determination of chlorine, sulphur and phosphorus in organic materials by ion chromatography using electrodialysis sample pretreatment, J. Chromatogr. A 704 (1995) 530-534.

[13] J.A. Nóbrega, M.C. Santos, R.A. de Sousa, S. Cadore, R.M. Barnes, M. Tatro, Sample preparation in alkaline media, Spectrochim. Acta Part B 61 (2006) 465-495.

[14] H. Haraguchi, K. Fuwa, Atomic and molecular absorption-spectra of indium in airacetylene flame, Spectrochim. Acta Part B 30 (1975) 535-545.

[15] K. Dittrich, B.Y. Spivakov, V.M. Shkinev, G.A. Vorobeva, Molecular absorption spectrometry by electrothermal evaporation in the graphite-furnace.10. Determination of chloride traces by $\mathrm{AlCl} \mathrm{MA}$ in graphite cuvettes after liquid-liquid extraction of chloride with triphenyltin hydroxide, Talanta 31 (1984) 341-345.

[16] M.D. Huang, H. Becker-Ross, S. Florek, U. Heitmann, M. Okruss, Determination of halogens via molecules in the air-acetylene flame using high-resolution continuum source absorption spectrometry, part II: chlorine, Spectrochim. Acta Part B 61 (2006) 959-964.

[17] U. Heitmann, H. Becker-Ross, S. Florek, M.D. Huang, M. Okruss, Determination of non-metals via molecular absorption using high-resolution continuum source absorption spectrometry and graphite furnace atomization, J. Anal. At. Spectrom. 21 (2006) 1314-1320.

[18] M. Fechetia, A.L. Tognon, M.A.M.S. da Veiga, Determination of chlorine in food samples via the $\mathrm{AlCl}$ molecule using high-resolution continuum source molecular absorption spectrometry in a graphite furnace, Spectrochim. Acta Part B 71-72 (2012) 98-101.

[19] B. Welz, F.G. Lepri, R.G.O. Araujo, S.L.C. Ferreira, M.-D. Huang, M. Okruss, H. BeckerRoss, Determination of phosphorus, sulfur and the halogens using high-temperature molecular absorption spectrometry in flames and furnaces - a review, Anal. Chim. Acta. 647 (2009) 137-148.

[20] B. Welz, M.G.R. Vale, D.L.G. Borges, U. Heitmann, Progress in direct solid sampling analysis using line source and high-resolution continuum source electrothermal atomic absorption spectrometry, Anal. Bioanal. Chem. 389 (2007) 2085-2095.

[21] B. Welz, H. Becker-Ross, S. Florek, U. Heitmann, M.G.R. Vale, High-resolution continuum-source atomic absorption spectrometry - what can we expect? J. Braz. Chem. Soc. 14 (2003) 220-229.

[22] B. Welz, High-resolution continuum source AAS: the better way to perform atomic absorption spectrometry, Anal. Bioanal. Chem. 381 (2004) 69-71.

[23] É.R. Pereira, I.N.B. Castilho, B. Welz, J.S. Gois, D.L.G. Borges, E. Carasek, J.B. de Andrade, Method development for the determination of bromine in coal using high-resolution continuum source graphite furnace molecular absorption spectrometry and direct solid sample analysis, Spectrochim. Acta Part B 96 (2014) 33-39.

[24] B. Welz, M.G.R. Vale, É.R. Pereira, I.N.B. Castilho, M.B. Dessuy, Continuum source atomic absorption spectrometry: past, present and future aspects - a critical review, J. Braz. Chem. Soc. 25 (2014) 799-821.

[25] P. Parvinen, L.H.J. Lajunen, Determination of chloride in drinking and ground water by $\mathrm{AlCl}$ molecular absorption spectrometry using graphite furnace atomic absorption spectrometer, Talanta 50 (1999) 67-71.
[26] M.R. Shepard, B.T. Jones, D.J. Butcher, High-resolution, time-resolved spectra of indium and aluminum atoms, fluorides, chlorides, and oxides in a graphite tube furnace, Appl. Spectrosc. 52 (1998) 430-437.

[27] E. Runge, E.K.U. Gross, Density-functional theory for time-dependent systems, Phys. Rev. Lett. 52 (1984) 997-1000.

[28] P. Hohenberg, W. Kohn, Inhomogeneous electron gas, Phys. Rev. 136 (1964) B864-B871.

[29] A.D. Becke, Density-functional exchange-energy approximation with correct asymptotic behavior, Phys. Rev. A 38 (1988) 3098-3100.

[30] C. Lee, W. Yang, R.G. Parr, Development of the Colle-Salvetti correlation-energy formula into a functional of the electron density, Phys. Rev. B 37 (1988) 785-789.

[31] F. Weigend, R. Ahlrichs, Balanced basis sets of split valence, triple zeta valence and quadruple zeta valence quality for $\mathrm{H}$ to $\mathrm{Rn}$ : design and assessment of accuracy, Phys. Chem. Chem. Phys. 7 (2005) 3297-3305.

[32] M. Kaupp, P.v.R. Schleyer, H. Stoll, H. Preuss, Pseudopotential approaches to Ca, Sr, and Ba hydrides. Why are some alkaline earth MX2 compounds bent? J. Chem. Phys. 94 (1991) 1360-1366.

[33] T. Petrenko, F. Neese, Efficient and automatic calculation of optical band shapes and resonance Raman spectra for larger molecules within the independent mode displaced harmonic oscillator model, J. Chem. Phys. 137 (2012) 234107.

[34] F. Neese, ORCA - An Ab Initio, Density Functional and Semiempirical Program Package, University of Bonn, 2008.

[35] G. Maroulis, Evaluating the performance of DFT methods in electric property calculations: sodium chloride as a test case, Rep. Theor. Chem. (2013) 1-8.

[36] Y. Zhao, D.G. Truhlar, Benchmark databases for nonbonded interactions and their use to test density functional theory, J. Chem. Theory Comput. 1 (2005) 415-432.

[37] Z. Grobenski, R. Lehmann, R. Tamm, B. Welz, Improvements in graphite furnace atomic absorption microanalysis with solid sampling, Microchim. Acta 1 (1982) $115-125$.

[38] U. Völlkopf, Z. Grobenski, R. Tamm, B. Welz, Solid sampling in graphite furnace atomic-absorption spectrometry using the cup-in-tube technique, Analyst 110 (1985) 573-577.

[39] J.S. de Gois, E.R. Pereira, B. Welz, D.L.G. Borges, Determination of chlorine in biological materials using electrothermal vaporization inductively coupled plasma mass spectrometry and direct solid sample analysis, Spectrochim. Acta Part B (2014), http://dx.doi.org/10.1016/j.sab.2014.09.005.

[40] H.U. Schütze-Pahlmann, C. Ryzlewicz, J. Hoeft, T. Törring, Millimeter wave spectra of the $2 \Sigma$ radicals SrF and SrCl, Chem. Phys. Lett. 93 (1982) 74-77.

[41] K.R. More, S.D. Cornell, The band spectra of $\mathrm{SrCl}$ and $\mathrm{SrH}$, Phys. Rev. 53 (1938) 806-811.

[42] S. Antrobus, D. Husain, J. Lei, F. Castaño, M.N.S. Rayo, Investigation of the molecular chemiluminescence $\mathrm{SrCl}(\mathrm{A} 2 \Pi 1 / 2,3 / 2, \mathrm{~B} 2 \Sigma+\rightarrow \mathrm{X} 2 \Sigma+$ ) and the atomic resonance fluorescence $\operatorname{Sr}(53 \mathrm{P} 1 \rightarrow 51 \mathrm{~S} 0)$ in the time-domain following the pulsed dye laser generation of $\mathrm{Sr}(53 \mathrm{PJ})$ in the presence of $\mathrm{CH}_{2} \mathrm{Cl}_{2}$, Int. J. Chem. Kinet. 27 (1995) 741-756.

[43] X. Mao, A.A. Bol'shakov, I. Choi, C.P. McKay, D.L. Perry, O. Sorkhabi, R.E. Russo, Laser ablation molecular isotopic spectrometry: strontium and its isotopes, Spectrochim. Acta Part B 66 (2011) 767-775. 